$\underline{\text { Iranian Journal of Pathology }}$ | ISSN: 2345-3656

\title{
Possible Interrelationship of Inflammatory Cells in Dry Type Cutaneous Leishmaniasis
}

\author{
Elham Taheri $^{1}$, Shahriar Dabiri ${ }^{1 *}$, Manzumeh Shamsi Meymandi ${ }^{1}$, Ebrahim Saedi $^{1}$
}

1. Dept. of Pathology, Pathology and Stem cell Research Center, Afzalipour Medical School, Kerman

\begin{tabular}{l} 
KEYWORDS \\
\hline Cutaneous Leishmaniasis \\
Macrophages \\
Dendritic Cells \\
\end{tabular}

Article Info

Received 15 Mar 2016;

Accepted 29 Aug 2016;

Published Online 2017;

\section{ABSTRACT}

Background \& Objective: There is a complicated interaction between leishmaniasis and the host immune cells, and also between the host immune cells. These interactions have fundamental effects on the outcome of the disease.

The current study aimed at characterizing the number, distribution, colocalization, and interrelation of 4 types of inflammatory cells in different clinical forms of dry-type cutaneous leishmaniasis (CL).

Methods: Thirty-nine cases of CL were studied. The cases were classified clinically as 14 cases of acute leishmaniasis with indurated papules, nodules, and plaques with central crust formation $<2$ years, 7 cases of chronic type with nonhealing lesions $>2$ years, and 12 cases of lupoid leishmaniasis with characteristic papules around previous scars of CL > 2 years. Paraffin-embedded blocks were stained with hematoxylin and eosin (H\&E) and also stained immunohistochemically for CD4, CD8, CD68, and CD1a.

Results: In acute CL, there was a significant correlation between CD68+ macrophages and CD1a+ epidermal dendritic cells (DCs); the population of CD68+ macrophages and CD1a+ epidermal DCs increased in parallel.

In lupoid CL, there was a significant correlation between CD1a+ epidermal DCs, and CD1a+ dermal DCs and population of CD1a+ epidermal DCs; the number of CD1a+ dermal DCs increased in parallel.

Conclusions: The result of the current study could be used as a baseline to design and study the new targeted therapy of synergistic effects of macrophages and DCs to phagocytizing leishmania bodies; and/or suggestion planning of individualizing setup of vaccine by autologous interaction of macrophages and DC in CL.

Corresponding Information: Shahriar Dabiri MD, Pathology and Stem cells Research Center, Department of Pathology, Afzalipour Medical School, Kerman, Iran. Email: dabiri12@yahoo.com

Copyright $\odot$ 2017, IRANIAN JOURNAL OF PATHOLOGY. This is an open-access article distributed under the terms of the Creative Commons Attributionnoncommercial 4.0 International License which permits copy and redistribute the material just in noncommercial usages, provided the original work is properly cited.

\section{Introduction}

Leishmaniasis is one of the most important parasitic disorders and a zoonotic disease characterized by parasitised mononuclear phagocytic system. It is considered a neglected disease by the World Health Organization (WHO), and is particularly common in tropical and subtropical regions (1). Cutaneous leishmaniasis (CL) is the most common form of leishmaniasis characterized by chronic skin lesions and permanent scars in the infected area (2).Epidemiological investigations indicated that
90\% of all reports of CL occurred in Afghanistan, Algeria, Saudi Arabia, Iran, Sudan, and Syria $(3,4)$.

At present, the diagnosis of CL is often made on the basis of epidemiologic and lesion characteristics, with the demonstration of the presence of the parasite in lesions (smear and Giemsa staining procedure), histopathological examination, isolation of Leishmania parasite from biopsies or aspirates in Novy-MacNeal-Nicolle 
(NNN) medium, serology, and molecular approaches (5).

It was previously proven that in $\mathrm{CL}$ the histopathological diagnosis varies from an inflammatory infiltrate of mononuclear cells and neutrophils, to granulomatous reactions with or without necrosis (6).

Several investigations attempted to establish the importance of histopathology in the diagnosis of CL; however, different morphological findings were found. In this context, it is proved that the cellular immune response plays an important role in pathogenesis of CL (7-9). T lymphocytes are the main agents in lymphocytic infiltration and control of parasite replication in CL (10-12). It seems that parasite growth control is mediated by inflammatory process. The interaction of parasitehost and that of different inflammatory cells, and the correlation between inflammatory cells may affect parasite load in lesion and histopathological changes of lesion (13-15). Immunohistochemical (IHC) studies showed that population of inflammatory cells in CL included CD4+ and CD8+ T-Cells and B-Cells, macrophages, and natural killer cells (NKC) (16-17). Morgado et al., showed an association between the clinical course and the population of inflammatory cells in CL (18).

The current study aimed at exploring the intercorrelation between different inflammatory cell types (CD4+ helper T-Cells, CD8+ cytotoxic T-Cells, CD68+ macrophages, and CD1a+ dendritic cells (DCs) in different forms of CL and describing the correlation between different inflammatory cells and histopathology of lesions.

\section{Material and Methods}

The current study was approved by Ethics Committee of Kerman University of Medical Sciences. It was a retrospective case series study on the patients with CL diagnosed in Afzalipour Institute of Medical Sciences, Kerman, Iran. The patients were diagnosed using the established clinical, epidemiological, and histopathological criteria ( 19). Patients were identified by the natural history of their disease and the presence of single or multiple lesions. Clinical diagnosis was parasitically confirmed by Giemsa, or haematoxylin and eosin (H\&E) staining of smears and biopsies, and/or polymerase chain reaction (PCR) assay. The patients were not under treatment at the time of study. Patients were divided into 3 groups based on the duration of disease:

1) Acute leishmaniasis ( $<24$ months: 14 patients)

2) Chronic leishmaniasis (> 24 months: 7 patients)

3) Lupoid leishmaniasis (presence of new lesions in the center or around the atrophic scar due to previous healed leishmaniasis: 12 patients)(20-23).

Skin biopsies were embedded in $10 \%$ formalin and paraffin blocks were prepared. Sections with 4 micrometer thickness were obtained and $\mathrm{H} \& \mathrm{E}$ staining was done.

\section{Antibodies}

On all biopsies, in addition to H\&E staining, 4 immunohistochemical markers were studied.The markers were monoclonal antibodies used for immunophenotypic characterization of leukocytes, directed to the following human cell surface antigens and included CD4 (code MU421-UC; clone 4B12), CD8 (code MU422-UC; clone1A5), CD1a (code MU490-UC; clone O10), and CD68 (code MU416-UC; clone KP1) (BioGenex company) ready to be used without dilution factor.

\section{Immunohistochemistry procedure}

Sections with 4 micrometer thickness were prepared. Slides were silanized to improve the adherence of tissue. After dewaxing and rehydrating paraffin sections, unmasking antigens with antigen retrieval was performed in $0.01 \mathrm{M}$ citrate buffer in microwave oven at $800 \mathrm{~W}$ for 10 minutes. Slides were cooled down to room temperature. Slides were washed quickly in Trisbuffered saline PH 7.4. Slides stained with antiCD4, anti-CD8, anti-CD68, and anti-CD1a antibodies and 3,3'-diaminobenzidine (DAB) chromogen. EnVision solution contain secondary antibody bind to the biotin and streptavidin bind to peroxidase were used.

\section{Leukocyte quantification}

Cells were counted using a light microscope (Olympus CX31) connected to a camera. All the fields of interest were counted in each section at a 
magnification of $400 \mathrm{X}$, giving 2 to $4 \times 10^{4}$ cells per section (24). Numbers of different inflammatory cells (cells $/ \mathrm{mm}^{2}$ ) were determined by an ocular micrometer and manual hematology cell counter. Langerhans cells (LCs) (CD1a), helper T-Cells (CD4), cytotoxic T-Cells (CD8), and macrophages (CD68) were counted. Totally, 1950 fields of IHC stained sections (10 fields per slide for each CD4, CD8, and CD68 markers and 20 fields per slide for CD1a marker) were counted by micrometer.

\section{Azadeh classification}

Histopathological patterns based on Azadeh classification (23) included 4 groups: Class 1, anergic histiocytes with many leishman bodies; class 2 , necrotizing granuloma with many plasma cells and few leishman bodies; class 3, organized epithelioid granuloma with few plasma cells and very occasional necrosis or leishman bodies; and class 4, necrotizing granuloma with stellate microabscess.

\section{Histopathological analysis}

The parameters of hyperkeratosis, parakeratosis, ulceration, acanthosis, exocytosis, abscess formation, spongiosis, apoptotic body, atrophy epidermis, melanophages collection, and pseudoepitheliomatous hyperplasia and congestion were reviewed based on previous studies of the histopathology of CL (25).

\section{Quantitative analysis}

Leishman body (parasite load) was reported in H\&E sections with micrometer based on Ridley scoring system as follows: absent (0), scattered visible only in oil immersion $(+)$, some visible in highly magnified slides $(400 \times)(2+)$, many visible in mildly magnified slides (3+) (26).

\section{Statistical analysis}

All the information was expressed as mean \pm standard error of the mean (SEM). The means were calculated based on individual values for each patient. Comparisons between the groups were made by the non-parametric Mann-Whitney test and the Student $t$ test for unpaired samples. The P-values $<0.05$ were considered significant. The Kruskal-Wallis non-parametric test was used to analyze the variance to compare variability within groups. Correlations between variables were analyzed using Spearman rank correlation coefficient. All tests were performed using SPSS version 17 (SPSS Inc., Chicago, IL, USA).

\section{Results}

Thirty-nine patients were included in the current study; the mean age of the participants was 34.5 years (ranging from 15 to 55 years); $52.4 \%$ of the participants were male and $47.9 \%$ female. Acute CL was observed in 17(43.6\%) cases, chronic CL in $8(20.5 \%)$, and lupoid CL in 14 (35.9\%); based on Azadeh classifications, 39.4\%, $24.2 \%, 27.3 \%$, and $9.1 \%$ of the cases were in class 1 , class 2, class 3 and class 4 , respectively. In quantitative analysis of leishman body on $\mathrm{H} \& \mathrm{E}$ sections, $30.3 \%, 15.2 \%, 12.1 \%$, and $12.1 \%$ were found in classes 1, 2, 3, and 4 of Azadeh classifications, respectively.

\section{Immunohistochemistry results}

CD68+ macrophages were frequent (25.82 \pm 9.6 cells $/ \mathrm{mm}^{2}$ ) and a significant correlation was observed between the number of them and lupoid form of CL $(\mathrm{P}<0.05)$.

The mean number of CD4+ helper T-Cells was $18.32 \pm 6.8$ cells $/ \mathrm{mm}^{2}$ and showed no correlation with the type of lesion.

CD 8+ cytotoxic T-Cells with the mean number of $26.33 \pm 8.6$ cells $/ \mathrm{mm}^{2}$ had no significant relationship with the type of lesion.

CD1a+ LCs were observed in the epidermis $\left(6.23 \pm 2.8\right.$ cells $\left./ \mathrm{mm}^{2}\right) \quad$ with their projections forming a network. Positive staining for these cells was also detected in the dermis $(2.8 \pm 1.5$ cells/ $\mathrm{mm}^{2}$ ), but limited to the papillary dermis. These cells also had no significant relationship with the type of lesion.

The co-localization of these 4 types of cells in respect to type of lesion was analyzed.

In acute $\mathrm{CL}$, there was a significant correlation between CD68+ macrophages and CD1a+ epidermal DCs. Population of CD68+ macrophages and CD1a+ epidermal DCs increased in parallel $(\mathrm{P}=0.027)$ (Figures 1 and 2). 


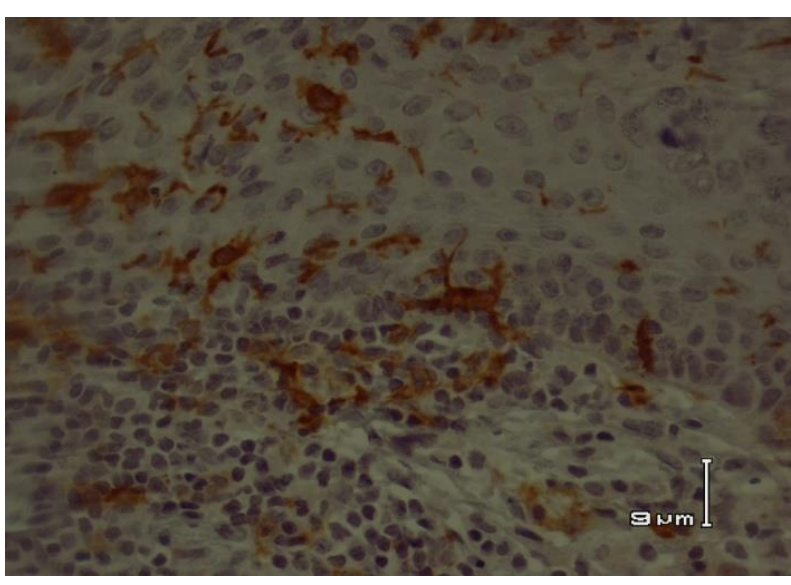

Fig 1. CD1a+ dendritic cells in acute cutaneous leishmaniasis

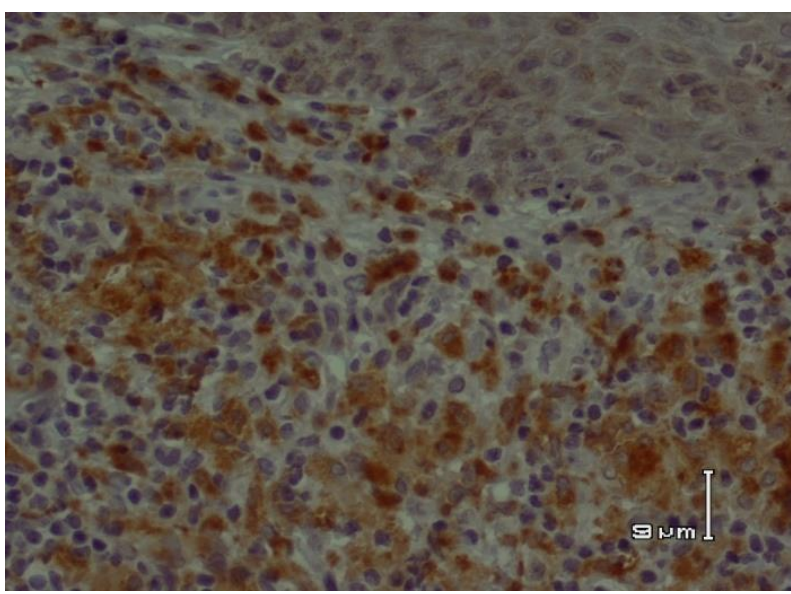

Fig 2. CD68+ macrophages in acute cutaneous leishmaniasis

In lupoid $\mathrm{CL}$, there was a significant correlation between CD1a+ epidermal DCs and CD1a+ dermal DCs. The population of CD1a+ epidermal DCs and CD1a+ dermal DCs increased in parallel $(\mathrm{P}=0.004)$ (Figure 3).

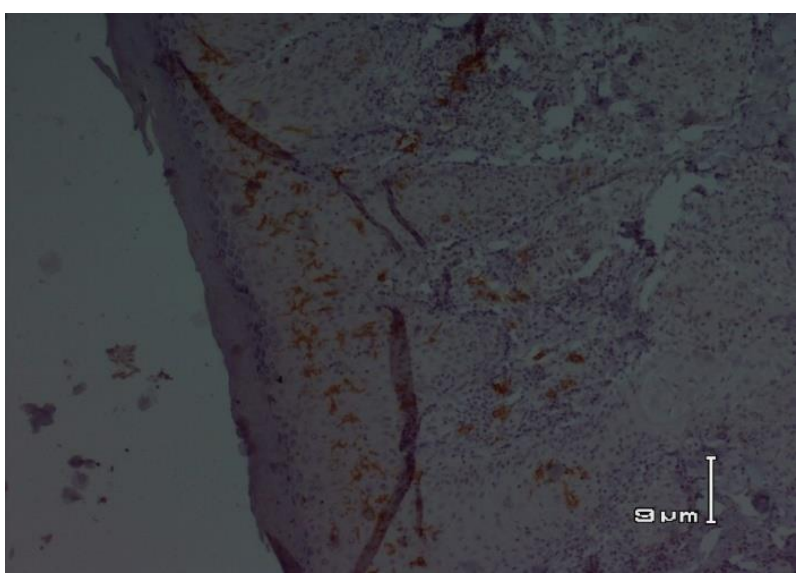

Fig 3. CD1a+ dendritic cells in lupoid cutaneous leishmaniasis
In all 3 forms, no other co-localization and interrelationship of inflammatory cells infiltrate were observed.

The possible correlation of CD4+ helper $\mathrm{T}$ Cells, CD8+ cytotoxic T-Cells, CD68+ macrophages, and CD1a+ DCs with various Azadeh classifications was evaluated. The obtained results showed a significant association between the presence of CD68+ macrophages and class 3 of Azadeh classification.

In quantitative analysis of leishman body on H\&E slides, no significant association was observed between inflammatory cells and load of leishman body.

There was no significant association between hyperkeratosis, parakeratosis, ulceration, acanthosis, exocytosis, abscess formation, spongiosis, apoptotic body, atrophy epidermis, melanophages collection, and pseudoepitheliomatous hyperplasia and congestion with CD4+, CD8+, and CD68+ cells; while there was a significant correlation between spongiosis and dermal $\mathrm{CD} 1 \mathrm{a}+(\mathrm{P}=0.013)$, and acanthosis and dermal CD1a+ $(\mathrm{P}=0.023)$.

\section{Discussion}

Leishmaniasis is caused by different species of genus Leishmania. Depending on the species, the parasite causes 3 different clinical presentations: cutaneous, mucocutaneous, and visceral leishmaniasis (27).

Cutaneous leishmaniasis (CL) is endemic in more than 98 countries, its overall prevalence is 12 million cases, and the annual incidence is 2 to 2.5 million cases (5). The parasite is transmitted by the bite of infected female sand flies, which inoculate the infective form of the parasite into the dermis of the host. Skin is the first point of contact with the protozoan, where the parasite is rapidly taken up by phagocytic cells. The skin is an important immune compartment that actively participates in host protection at both the early and later phases of infection. A wide variety of cells including neutrophils, macrophages, immature DCs, $\mathrm{T}$ lymphocytes and CLs provide considerable capacity to generate and maintain local immune reactions $(8,28)$. 
The current study evaluated the immunological and histological arrangements, and interrelationship of some important immune cells involved in the outcome of $\mathrm{CL}$ at the levels of acute, chronic, and lupoid forms .The inflammatory cells consisted of CD4+ helper TCells, CD 8+ cytotoxic T-Cells, CD68+ macrophages, and CD1a+ DCs.

As skin is an important site to transmit the leishmaniasis, the study on the immune responses of patients infected with CL and its association with distinct levels of leishman body load, and duration of $\mathrm{CL}$ allows new insights that elucidate the progressive or protective mechanisms of the infection(29).

The current study showed that acute CL had significant correlation between CD68+ macrophages and CD1a+ epidermal DCs and population of $\mathrm{CD} 68+$ macrophages and CD1a+ epidermal DCs increased in parallel during acute $\mathrm{CL}(\mathrm{P}=0.027)$.

It is definite that Leishmania parasites interact and infect a variety of host cell types, CD68+ macrophages and CD1a DCs are the most important cells that regulate the outcome of infection. After the initial uptake of promastigotes by macrophages into the phagosome, subsequent fusion with lysosomes occurs, and the parasites should survive in this phagolysosomal environment. This is perhaps one of the most challenging environments for most pathogens, and Leishmania parasites are among the few protozoa that can survive and multiply in such an environment. Understanding how these organisms are able to survive and manipulate host cells to favor their replication and transmission is critically important to design new drugs or therapeutic strategies against the disease (30-33).

Leishmania spp. are obligatory intracellular pathogens; macrophages are mandatory for parasite survival. After initial infection, both neutrophils and macrophages are recruited to the lesion, and their interactions with the parasites significantly influence the outcome of infection $(34,35)$. However, recent studies suggest that more neutrophils are recruited to the infection site and these cells are very efficient in early parasite uptake (36).
Macrophages that phagocytosed parasites are the last host cells for parasite replication and also the effector cells responsible for the destruction of parasites. Macrophages could be activated by different signals. Thus, suitable activation of macrophages is vital to eliminate leishmaniasis as an intracellular pathogen. The products of $\mathrm{CD} 4+\mathrm{T}$ helper1 (Th1) cells and NK cells mediate classical activation of macrophages.

On the other hand, to evade killing by activated macrophages, Leishmania parasite should manipulate the macrophage activation pathways in a manner that favor their survival and proliferation. Interleukin (IL)-12 is a critical cytokine required for $\mathrm{CD} 4^{+} \mathrm{Th} 1$ development and production of IFN- $\gamma$ (37). IL-12 is mainly produced by antigen-presenting cells (APCs), and macrophages were initially proposed as the major source of IL-12. There is evidence that macrophage ability to produce IL-12 is selectively impaired by the parasites (38-39).

DCs are hematopoietic bone marrow derived leukocytes that are widely distributed all over the body (40). DCs are specialized in uptaking, processing, and presenting antigens to $\mathrm{T}$-Cells. Macrophages are also professional APCs and the main host to harbor Leishmania parasites and effector cells for parasite killing, but macrophages infected with Leishmania parasites do not secrete IL-12 (41) and, hence, are unable to stimulate antigen-specific $\mathrm{CD}^{+}$Th1 cell response (42). Indeed, several reports show a central role for DCs in organizing immune responses in leishmaniasis $(41,43)$.

The current study showed that DCs and macrophages might regulate the outcome of leishmaniasis, which was consistent with the results of other studies.

Following the infection, both the macrophages and DCs phagocytose leishman bodies lead to different functional outcomes. Infected DCs produce IL-12, which is critical to develop IFN- $\gamma$ producing CD4+ cells. IFN- $\gamma$ affects the infected macrophage; leading to the activation (classical activation), and production of nitric oxide and other free radicals that are important for intracellular parasite killing $(44,45)$. 
The current study showed that in lupoid CL, there was a significant correlation between CD1a+ epidermal DCs and CD 1a+ dermal DCs; and the population of CD 1a+ epidermal DCs and CD 1a+ dermal DCs increased in parallel $(\mathrm{P}=0.004)$.

DCs interdigitate the processes between epidermal keratinocytes, and comprise approximately $2 \%$ of the cell density of the epidermis. These cells are found in many epithelia, which are in contact with the external environment (46).

Meymandi et al. identified amastigotes of Leishmania spp. within the cytoplasm of intraepidermal DCs. In addition, transepithelial elimination of amastigotes of Leishmania spp. in CL was described $(21,47)$.

After the initiation of $L$. major infection, the local inflammatory response induces DCs to cross the dermoepidermal junction to allow phagocytosis of parasites in the dermis $(20,4421,48)$.

The current study showed that predominant lymphocyte was CD8+ cytotoxic T-Cells supported by previous studies $(25,40,50)$.

CD8 $\mathrm{T}$ cells producing IFN- $\gamma$ are important to modulate the $\mathrm{CD} 4 \mathrm{~T}$ cell response.

The depletion of CD8 T-Cells did not interfere with the proliferative ability of CD4 T-Cells, but a reduction was observed in the percentage of CD4 T-Cells producing IFN- $\gamma$, and this effect was associated with an increase in parasite load in mice, suggesting an interaction between CD4 and CD8 T-Cells (51). In human leishmaniasis, important roles of CD8 T-Cells in the healing process through IFN- $\gamma$ production (52) and in resistance to the infection are described (53).

The current study found a significant correlation between Azadeh class 3 lesions and CD68+ macrophages.

In the current study, the predominant cells in classes 1 and 2 of Azadeh classification were CD1a+ DCs, supported by other studies (21).

There was a significant relationship among dermal CD1a+ DCs, spongiosis, and acanthosis. As mentioned in the previous studies, cutaneous infection by $L$. major and resulting local inflammatory response induces DCs to cross the dermoepidermal junction to allow phagocytosis of parasites in the dermis $(21,54)$, and this fact may result in the histopathological findings of the current study.

The current study characterized the inflammatory cells interrelation and $\mathrm{Co}_{-}$ localization of the infiltrate in different skin lesions of CL. In conjunction with the results of other investigations, the current study results provided strong evidence that LCs of epidermal origin may be one of the essential parts of an effective immune response against $\mathrm{CL}$. Furthermore, the current study demonstrated that LCs traversing the dermoepidermal junction contain amastigotes of Leishmania spp. within the cytoplasm. The result of the current study can be used as a baseline to design and assess new targeted therapies and/or planning individualized set up of vaccine by self-interaction of macrophages and DC in CL.

\section{Acknowledgment}

Authors thank Mrs. Sheikh Shoaee, for her excellent technical assistance.

\section{Conflict of interest}

The authors declared no conflict of interest.

\section{References}

1. WHO | Leishmaniasis. World Health Organization; [cited 2016 Mar 12]. Available from:

http://www.who.int/mediacentre/factsheets/fs375/e $\mathrm{n} /$

2. Desjeux P. Leishmaniasis: current situation and new perspectives. Comp Immunol Microbiol Infect Dis. 2004;27(5):305-18.

3. Mahmoudvand H, Saedi Dezaki E, Ezatpour B, Sharifi I, Kheirandish F, Rashidipour M. In vitro and In vivo antileishmanial activities of Pistacia vera essential Oil.Planta Medica 2016; 82(4): 279-84.

4. Salam N, Al-Shaqha WM, Azzi A. Leishmaniasis in the middle East: incidence and epidemiology. PLoS Negl Trop Dis. 2014;8(10):e3208.

5. de Vries HJC, Reedijk SH, Schallig HDFH. Cutaneous leishmaniasis: recent developments in diagnosis and management. Am J 
Clin Dermatol. 2015;16(2):99-109.

6. Palatnik-de-Sousa CB. Vaccines for Canine Leishmaniasis. Front Immunol. 2012; 3: 69.

7. Pirmez C, Yamamura M, Uyemura K, Paes-Oliveira M, Conceição-Silva F, Modlin RL. Cytokine patterns in the pathogenesis of human leishmaniasis. J Clin Invest. 1993;91(4):1390-5.

8. Meymandi S, Dabiri S, Shamsi-Meymandi M, Nikpour H, Kharazmi A. Immunophenotypic pattern and cytokine profiles of dry type cutaneous leishmaniasis

Arch Iran Med. 2009 Jul;12(4):371-6.

9. Díaz NL, Arveláez FA, Zerpa O, Tapia FJ. Inducible nitric oxide synthase and cytokine pattern in lesions of patients with American cutaneous leishmaniasis. Clin Exp Dermatol. 2006;31(1):114-17.

10. Gimblet C, Loesche MA, Carvalho L, Carvalho EM, Grice EZ, Artis D, Scott P. IL22 protects against tissue damage during cutaneou

s leishmaniasis. PLoS One. 2015; 10(8): e0134698.

11. Bangert C, Brunner PM, Stingl G. Immune functions of the skin.Clin Dermatol. 2011; 29(4): 360-76.

12. Christoph T, Müller-Röver S, Audring H, Tobin DJ, Hermes B, Cotsarelis G, et al. The human hair follicle immune system: cellular composition and immune privilege. Br J Dermatol. 2000;142(5):862-73.

13. Bogdan C, Röllinghoff $M$. How do protozoan parasites survive inside macrophages? Parasitol Today. 1999;15(1):22-8.

14. Belkaid Y, Hoffmann KF, Mendez S, Kamhawi S, Udey MC, Wynn TA, et al. The role of interleukin (IL)-10 in the persistence of Leishmania major in the skin after healing and the therapeutic potential of anti-IL-10 receptor antibody for sterile cure. J Exp Med. 2001;194(10):1497-506.

15. Gaze ST, Dutra WO, Lessa M, Lessa H, Guimarães LH, Jesus AR de, et al. Mucosal leishmaniasis patients display an activated inflammatory T-cell phenotype associated with a nonbalanced monocyte population. Scand J Immunol. 2006;63(1):70-8.

16. Esterre P, Dedet JP, Frenay C, Chevallier M, Grimaud JA. Cell populations in the lesion of human cutaneous leishmaniasis: a light microscopical, immunohistochemical and ultrastructural study. Virchows Arch A Pathol Anat Histopathol. 1992;421(3):239-47.

17. Da-Cruz AM, Oliveira-Neto MP, Bertho AL, Mendes-Aguiar CO, Coutinho SG. T cells specific to leishmania and other nonrelated microbial antigens can migrate to humanleishmaniasis skin lesions.J Invest Dermatol. 2010;130(5):1329-36.

18. Morgado FN, Schubach A, Rosalino CM V, Quintella LP, Santos G, Salgueiro M, et al. Is the in situ inflammatory reaction an important tool to understand the cellular immune response in American tegumentary leishmaniasis? $\mathrm{Br} \quad \mathrm{J}$ Dermatol. 2008; 158(1):50-8.

19. Diaz NL, Zerpa O, Ponce L V, Convit J, Rondon a J, Tapia FJ. Intermediate or chronic cutaneous leishmaniasis: leukocyte immunophenotypes and cytokine characterisation of the lesion. Exp Dermatol. 2002;11(1):34-41.

20. Salman SM, Rubeiz NG, Kibbi AG. Cutaneous leishmaniasis: clinical features and diagnosis. Clin Dermatol. 1999;17(3):291-6.

21. Meymandi S, Dabiri S, Dabiri D, Crawford RI, Kharazmi A. A quantitative study of epidermal Langerhans cells in cutaneous leishmaniasis caused by Leishmania tropica. Int $\mathbf{J}$ Dermatol. 2004;43(11):819-23.

22. Elder DE, Elenitsas R, Johnson BL M, GF. Lever's Histopathology of the skin. In: 9th ed. Philadelphia: Philadelphia Lippincott Williams \& Wilkins; 2007. p. 835-8.

23. Azadeh B, Samad A, Ardehali S. Histological spectrum of cutaneous leishmaniasis due to Leishmania tropica. Trans R Soc Trop Med Hyg. 1985;79(5):631-6.

24. ShamsiMeymandi S, Javadi A, Dabiri S, Shamsi Meymandi M, Nadji M.

Comparative histological and immunohistochemical changes of dry type cutaneous leishmaniasis after administration of meglumine antimoniate, imiquimod or combination therapy.Arch Iran Med. 2011 Jul;14(4):238-43.

25-Eslamamesh Shamsi Meymandi S, Eslam Manesh F, Dabiri Sh, Shamsi Meymandi M,Nadji M. The histopathological changes and immunohistochemical findings of acute, chronic non lupoid and chronic lupoid types of cutaneous 
leishmaniasis. J KUMS. Fall 2010, Vol 17, No 4:281-296.

26. Ridley DS. A histological classification of cutaneous leishmaniasis and its geographical expression. Trans $\mathrm{R}$ Soc Trop Med Hyg. 1980;74(4):515-21.

27. Georgiadou SP, Makaritsis KP, Dalekos GN. Leishmaniasis revisited: Current aspects on epidemiology, diagnosis and treatment. 2015;3(2):43-50.

28. Lakhal-Naouar I, Slike BM, Aronson NE, Marovich MA. The immunology of a healing response in cutaneous leishmaniasis treated with localized heat or systemic antimonial therapy. PLoS Negl Trop Dis. Public Library of Science; 2015 20;9(10):e0004178.

29. Lakhal-Naouar I, Slike BM, Aronson NE, Marovich MA. The immunology of a healing response in cutaneous leishmaniasis treated with localized heat or systemic antimonial therapy.PLoS Negl Trop Dis. 2015 20; 9(10): e0004178.

30. Gregory DJ, Olivier M. Subversion of host cell signalling by the protozoan parasite Leishmania. Parasitology. 2005;130: 27-35.

31. Olivier M, Gregory DJ, Forget G. Subversion mechanisms by which Leishmania Parasites can escape the host immune response: a signaling point of view. Clin Microbiol Rev. 2005;18(2):293-305.

32. Xin L, Li K, Soong L. Down-regulation of dendritic cell signaling pathways by Leishmania amazonensis amastigotes. Mol Immunol. 2008;45(12):3371-82.

33. Isnard A, Shio MT, Olivier M. Impact of Leishmania metalloprotease GP63 on macrophage signaling. Front Cell Infect Microbiol. 2012;2:72.

34. Ribeiro-Gomes FL, Moniz-de-Souza MCA, Alexandre-Moreira MS, Dias WB, Lopes MF, Nunes MP, et al. Neutrophils activate macrophages for intracellular killing of Leishmaniamajor through recruitment of TLR4 by neutrophil elastase. J Immunol. 2007;179(6):3988-94.

35. Dabiri Sh, Hayes M.M.M>, Shamsi Meymandi S, Basiri M, Soleimani F, Mosavi M.R. Cytologic features of dry type cutaneous leishmaniasis. Diagnostic Cytopathology. 1998, Vol 19. No 3 : 182-185
36. Peters NC, Sacks DL. The impact of vector-mediated neutrophil recruitment on cutaneous leishmaniasis. Cell Microbiol. 2009;11(9):1290-6.

37. Mosmann TR, Coffman RL Heterogeneity of cytokine secretion patterns and functions of helper $\mathrm{T}$ cells. Adv Immunol. 1989;46:111-47.

38. Pirdel L, Hosseini AZ, Rasouli M. Immune response in susceptible $\mathrm{BALB} / \mathrm{c}$ mice immunized with DNA encoding Lipophosphoglycan 3 of Leishmania infantum.Parasite Immunol. 2014; 36(12):700-7.

39. Srivastav S, Kar S, Chande AG, Mukhopadhyaya R, Das PK. Leishmaniadonovani exploits host deubiquitinatin $\mathrm{g}$ enzyme A20, a negative regulator of TLR signaling, to subvert host immune response.J Immunol. 2012; 189(2): 924-34.

40. Steinman RM. Dendritic cells: Understanding immunogenicity. Eur J Immunol. 2007;37:53-60.

41. von Stebut E, Belkaid Y, Jakob T, Sacks DL, Udey MC. Uptake of Leishmania major amastigotes results in activation and interleukin 12 release from murine skin-derived dendritic cells: implications for the initiation of anti-Leishmania immunity. J Exp Med. 1998;188(8):1547-52.

42. Kima PE, Soong L, Chicharro C, Ruddle $\mathrm{NH}$, McMahon-Pratt D. Leishmania-infected macrophages sequester endogenously synthesized parasite antigens from presentation to $\mathrm{CD} 4+\mathrm{T}$ cells. Eur J Immunol. 1996;26(12):3163-9.

43. León B, López-Bravo M, Ardavín C. Monocyte-derived dendritic cells formed at the infection site control the induction of protective $\mathrm{T}$ helper 1 responses against Leishmania. Immunity. 2007;26(4):519-31.

44. Liu D, Uzonna JE. The early interaction of Leishmania with macrophages and dendritic cells and its influence on the host immune response. Front Cell Infect Microbiol. 2012;2:83.

45. Meymandi S, Dabiri S, Dabiri D, Crawford RI, Kharazmi A. A quantitative study of epidermal Langerhans cells in cutaneous leishmaniasis caused by Leishmania tropica. Int $\mathrm{J}$ Dermatol. 2004;43(11):819-23.

46. Gilliam AC, Kremer IB, Yoshida Y, Stevens SR, Tootell E, Teunissen MB, et al. The human hair follicle: a reservoir of CD40+ B7- 
deficient Langerhans cells that repopulate epidermis after UVB exposure. J Invest Dermatol. 1998;110(4):422-7.

47. Azadeh B, Abdulla F. Transepithelial elimination in cutaneous leishmaniasis. Acta Derm Venereol. 1995;75(2):159.

48. Solbach W, Laskay T. The host response to Leishmania infection. Adv Immunol. 2000;74:275-317.

49. Nathan CF, Murray HW, Wiebe ME, Rubin BY. Identification of interferon-gamma as the lymphokine that activates human macrophage oxidative metabolism and antimicrobial activity. J Exp Med. 1983;158(3):670-89.

50. Da-Cruz AM, Oliveira-Neto MP, Bertho $\mathrm{AL}$, Mendes-Aguiar CO, Coutinho SG. T cells specific to leishmania and other nonrelated microbial antigens can migrate to human leishmaniasis skin lesions. J Invest Dermatol. 2010;130(5):1329-36.

51. Herath S, Kropf P, Müller I. Cross-talk between $\mathrm{CD} 8(+)$ and $\mathrm{CD} 4(+) \mathrm{T}$ cells in experimental cutaneous leishmaniasis: CD8(+) T cells are required for optimal IFN-gamma production by $\mathrm{CD} 4(+) \mathrm{T}$ cells. Parasite Immunol. 2014;25:559-67.

52. Da-Cruz AM, Conceição-Silva F, Bertho AL, Coutinho SG. Leishmania-reactive CD4+ and $\mathrm{CD} 8+\mathrm{T}$ cells associated with cure of human cutaneous leishmaniasis. Infect Immun. $1994 ; 62(6): 2614-8$.

53. Crauwels P, Bohn R, Thomas M, Gottwalt S, Jäckel F, Krämer S, Bank E, Tenzer S, Walther P, Bastian M, van Zandbergen G. Apoptotic-like Leishmania exploit the host's autophagy machinery to reduce T-cell-mediatedparasite elimination.Autophagy. 2015;11(2):285-97.

54- Moll H, Flohé S. Dendritic cells induce immunity to cutaneous leishmaniasis in mice. Adv Exp Med Biol. 1997;417:541-5.

\section{How to Cite This Article:}

Taheri E, dabiri S, Shamsi Meymandi M, Saedi E. Possible Interrelationship of Inflammatory Cells in Dry Type Cutaneous leishmaniasis. Iran J Pathol. 2017;12(2):119-127. 